\title{
TOWARDS A PEOPLE-FIRST ENGINEERING DESIGN APPROACH. A COMPREHENSIVE ONTOLOGY FOR DESIGNING INCLUSIVE ENVIRONMENTS
}

\author{
Fernandez, Claudia (1); \\ Zallio, Matteo (2); \\ Berry, Damon (1); \\ McGrory, John (1) \\ 1: Technological University Dublin; \\ 2: University of Cambridge
}

\begin{abstract}
The world is ageing, and this change will strongly impact the design of products, services and environments. Notwithstanding the proliferation of research initiatives, guidelines, policies and regulations, there is still a significant gap and lack of a uniformed strategy to guide engineers, designers, and architects to design inclusive environments. This article explores and summarizes through a review of international regulations and standards, the requirements that design practitioners need to consider when designing accessible, inclusive, smart, age-friendly environments. With this explorative study, we reviewed documentation and developed a comprehensive ontology comprised of people and design related criteria aiming to support the design of inclusive, smart and accessible buildings. The ontology was created by interpreting the criteria through semantics used in peoplecentered design approaches, where people's needs and design requirements are two fundamental phases for designing inclusively.

The results are intended to enable researchers and practitioners to better identify clusters of accessibility and inclusion criteria to facilitate the study and the design of accessible, inclusive, smart, age-friendly environments.
\end{abstract}

Keywords: Design methods, User centred design, Inclusive design, Building Accessibility Features, Comprehensive Ontology.

\author{
Contact: \\ Zallio, Matteo \\ University of Cambridge \\ Department of Engineering \\ United Kingdom \\ mz461@cam.ac.uk
}

Cite this article: Fernandez, C., Zallio, M., Berry, D., McGrory, J. (2021) 'Towards a People-First Engineering Design Approach. A Comprehensive Ontology for Designing Inclusive Environments', in Proceedings of the International Conference on Engineering Design (ICED21), Gothenburg, Sweden, 16-20 August 2021. DOI:10.1017/pds.2021.579 


\section{INTRODUCTION}

In 2019, the United Nations (UN) reported that the scales of balance in the age divide had tipped, where persons aged 65 or above have outnumbered children under five years of age globally (United Nations Department of Economic and Social Affairs, 2019). The UN estimates that by 2030 the number of older adults (people aged 65+) in the world will be 1.4 billion, with the population of those over 80 tripling by 2050 (United Nations Department of Economic and Social Affairs, 2019). The ageing process and increasing visibility of effects of ageing on the human body, will affect the needs and capabilities of the population (United Nations Department of Economic and Social Affairs, 2020). This will strongly influence the design process for developing products, services and environments that are tailored to an individual's needs. Furthermore, it poses clear evidence that citizens should play a greater role in the design process and become themselves protagonists that can make better informed design decisions.

The UN Sustainable Development Goals (UN-SDG) are a list of cross cutting thematic areas where effort should be emphasized to create a better society for the ageing world. Some of the 17 UN-SDG topics strongly propose the improvement of life in sustainable cities \& communities by innovating infrastructure, in order to guarantee health \& well-being of people of different ages (United Nations Development Program, 2016). According to the World Health Organisation (WHO), sustainable agefriendly environments and communities provide effective support for well-being \& socialisation (WHO, 2014). Both the UN-SDG and WHO guidelines impact the design and development of spaces where human beings spend most of their life: the rural/urban space and the built environment. Examples of recent community-oriented activities towards meeting these goals in the European context include the European Innovation Partnership on Active and Active Ageing: Age-Friendly Environments (EIP on AHA), the Thematic Network on Smart Healthy Age Friendly Environments (TN SHAFE), and several Framework Programme Eight projects such as the EU-SHAFE (EU SHAFE, 2019), the Hands on SHAFE (Hands-on SHAFE, 2019), and the NET 4 AGE-FRIENDLY action (NET 4 AGE-FRIENDLY, 2020) supported by the European Commission.

Designing communities and environments for ageing in place is a people-oriented process that plays an important role for sustainable urban growth and economic resilience (Lyons et al., 2016). The concept of 'ageing in place' and the centrality of 'place' in the ageing process are key elements for understanding processes associated with people exclusion (Mahmood and Keating, 2012). Notwithstanding the proliferation of research initiatives as well as the large quantity of informative material, guidelines, policies and regulations, there is still a significant awareness gap and lack of a uniformed strategy to guide engineers, designers, architects, and planners to design with a people-first approach.

This article, part of a project financed under the European Union's Horizon 2020 research and innovation programme, aims to explore and map the features that practitioners need to consider when designing environments, products or services that enable to age in place.

The main goal of this explorative study is to methodologically review key documents such as international regulations and standards and extract fundamental knowledge to facilitate the implementation of appropriate design strategies for the development of future spaces and solutions.

We seek to analyse the state of the art of building design regulations, to map and summarize peoplerelated and design-related parameters, and to create an ontology by interpreting them through semantics used in people-centred design approaches, where people's needs, and design requirements are two fundamental phases for designing inclusively.

\section{THE RELATIONSHIP BETWEEN DESIGN APPROACHES AND GUIDELINES}

Designing for an ageing society is part of a coherent sustainable development strategy (WHO, 2019). To achieve this goal, architects and design engineers will have to evolve their design process and shift towards a people-centred perspective. People-centred design processes are founded on exploring and understanding people's needs and their capabilities in order to create the design of new products and experiences, through a set of design requirements (Patnaik and Becker, 2010).

To fully embrace a people-centred design practice, which is inclusive, and where a variety of people's needs are met, it is essential to acquire strong emphatic skills, understanding of human capabilities 
(Thomas and McDonagh, 2013), awareness of design processes, and to comply with standards, regulations and policies at a g-local level (Zallio et al., 2016).

Everyone has different needs and priorities, so it is acknowledged that engineers, designers and architects should aim for a holistic, pan-disciplinary, inclusive approach when designing environments (Centre for Excellence in Universal Design, 2012). Inclusive design has been widely promoted in the last few years in various areas of research and business practice: "designing inclusively is no longer an option for companies. It is a business essential. Exclusivity is out, inclusivity is in." (Keates et al., 2004). By designing inclusively, designers are more inclined to provide flexible and adaptable mainstream solutions to the widest range of customers, by targeting a high level of well-being and user satisfaction (Keates et al., 2004). However, Inclusive Design (ID) didn't have a widespread impact on the whole architectural design practice (Heylighen et al., 2017).

To support engineers, architects and designers and to guarantee improvements in accessible and ID practice in the last three decades, a large number of acts, international standards and regulations have been developed across the world. Starting from the American context with the development of the Americans with Disabilities Act (ADA) in 1990, a series of acts and regulations quickly flourished in the European design community. In 1994 the ISO/TR 9527:1994 (Building construction - Needs of disabled people in buildings - Design guidelines) was the first standard developed by the International Standards Organization (ISO) (International Standards Organization, 1994) to address the needs of a large community of individuals, according to accessibility and inclusivity criteria.

Other documents followed. The Disability Discrimination Act (1995) (British Government, 1995), the ISO/IEC Guide 71:2001 (Guidelines for standards developers to address the needs of older persons and persons with disabilities) (International Standards Organization, 2001), the Building Regulations 2004 - Access and use of buildings part M (British Government, 2004), the ISO/TR 22411:2008 (Ergonomics data and guidelines for the application of ISO/IEC Guide 71 to products and services to address the needs of older persons and persons with disabilities) (International Standards Organization, 2008), the BS 8300:2009 (Design of an accessible and inclusive built environment. Buildings. Code of practice) (British Standard Institute, 2009), the code Building for Everyone: A Universal Design Approach from the Centre for Excellence in Universal Design in 2012 (Centre for Excellence in Universal Design, 2012), and the Universal Design Guidelines for Homes in Ireland (Centre for Excellence in Universal Design, 2015) are some of the milestones in area of designing inclusively for everyone.

The number of regulations and guidelines developed so far is a promising element that highlights how much attention was paid to the challenges of inclusivity in product and architectural design. The wide variety and large number of international and local regulations, as well as dissemination strategies, may constitute barriers for design professionals who wish to effectively employ these regulations to facilitate a daily, inclusive, working practice.

\section{METHODOLOGY}

\subsection{An exploratory map of the state of the art}

To foster understanding and adoption of a more ID practice for dwellings, it is scientifically relevant to map current and impactful guidelines, regulations, and standards commonly applied to the built environment. To this end, a state-of-the-art review (Grant and Booth, 2009) was conducted, with a focus on the most recent and appropriate building regulations on accessibility, disability and inclusion. Manuscript analysis was performed in accordance with Bowen guidelines (Bowen, 2009) where works are evaluated based on their relevance for the European setting, validity and content comprehensiveness. The time frame of the search spanned between 1993 and 2020. Although there are previous works related to accessibility in the built environment since 1970 (Van Ditmarsch, 2001) we observed that 1993 is a milestone in the specific domain area, as it coincides with the UN General Assembly's first framework focused on the equalization of opportunities for persons with disabilities (United Nations Department of Economic and Social Affairs, 1993).

Out of an initial search performed on regulations repositors such as the ISO (International Standard Organization), BSI (British Standard Institute), NSAI (National Standard Authority of Ireland), CEN/CENELC (European Committee for Standardization/the European Committee for Electrotechnical Standardization), DIN (Deutsches Institut für Normung), NEN (Nederlands Normalisatie Instituut), and Afnor (Association Française de Normalisation), 32 pivotal documents were identified. 
After a first pass analysis of title and introduction was completed, further iterative passes were performed which included criteria associated with theories of Universal Design (UD) and Inclusive Design (ID), rather than purely on accessibility and disability. We documented that, with the time progression, regulations, their titles and descriptions have uncoupled simply addressing disabilityrelated challenges to include approaches more commonly utilised in the domain of universal and inclusive methodologies.

Out of this selection, six of the most impactful, inclusive and exhaustive manuscripts were critically analysed. The ISO/TR 22411:2008 (Ergonomics data and guidelines for the application of ISO/IEC Guide 71 to products and services to address the needs of older persons and persons with disabilities) (International Standards Organization, 2008) released in 2008, the ISO 21542:2011 (Accessibility and usability of the built environment) (International Standards Organization, 2011), released in 2011, the guideline Building for Everyone: A Universal Design Approach from the Centre for Excellence in Universal Design - Ireland (Centre for Excellence in Universal Design, 2012), released in 2012, the CEN/CENELEC Guide 6:2014 (Guide for addressing accessibility in standards) (CEN and CENELEC, 2014), released in 2014, and the updated Universal Design Guidelines for Homes in Ireland (Centre for Excellence in Universal Design, 2015), released in 2015, and the BS 8300-1|2:2009 (Design of an accessible and inclusive built environment. Buildings. Code of practice) (British Standard Institute, 2009) from the British Standards Institute and its updated version from 2018.

\subsection{Analytical summary of people related and design related criteria}

To develop a detailed summary of people related and design related criteria for the built environment, including people's capabilities (assimilated to user needs in the people-centred design process) and accessibility and inclusion features (assimilated to design requirements in the people-centred design process) an analytical review was enforced.

First, we defined capabilities criteria of users/residents based on the CEN/CENELEC Guide 6:2014 and the ISO/TR 22411:2008. Both documents constituted these criteria based on the International Classification of Functioning (ICF) (World Health Organisation, 2001). We then outlined accessibility and inclusion criteria for dwellings, based on the ISO/TR 22411:2008, the ISO 21542:2011, the Building for Everyone, the Universal Design Guidelines for Homes in Ireland and the BS 8300-1|2:2009 documents.

After an analytical indexing of the documents, people related and design related features for the built environment were extrapolated to create two preliminary catalogues: one focused on people's needs, and one for dwellings design requirements. In case that the features were present in multiple documents they were highlighted and marked as correspondent feature. Other descriptors that were not present were cross correlated as an additional feature to consider. Through the process, a series of recurring patterns were identified. This allowed the creation of categories and assimilation of features through an Analytical Hierarchy Process (AHP). This method enabled the creation of a hierarchical representation of a system (Saaty, 1987) and a breakdown of the categories into smaller subclassifications, while showing the functional relationships between these elements within the system. Most importantly our methodology presented a clear roadmap of progressively improved user centric solutions from which the designer can choose what is desired to accomplish a people-centred design.

Through the AHP a comprehensive ontology, comprised of people related criteria and a wide-ranging diagram of design related features, was created to critically summarise the content of the analysed documents. Finally, we deployed the ontology through a graphical representation to explore the applicability on a wider scale.

\subsection{People related criteria}

The categorization of people related criteria refers to people's capabilities and was framed through three different layers. The first layer includes group (a) physical, group (b) sensorial, and group (c) cognitive abilities. The second layer includes under physical capabilities (group a): upper body movements (a.1), lower body movements (a.2), body size (a.3), voice and speech (a.4), and muscle power and endurance (a.5). Under sensorial capabilities (group b): hearing (b.1), seeing (b.2), taste and smell (b.3), touch (b.4). Under cognitive abilities (group c): global (c.1), affective (c.2), specific (c.3).

The third layer includes under physical capabilities (group a) and upper body movements (a.1): dexterity (a.1.1), manipulation (a.1.2), and rotation (a.1.3). 
Under lower body movements (a.2): balance (a.2.1). Under muscle power and endurance (a.5): grip strength (a.5.1), lift strength (a.5.2), pushing force with two hands (a.5.3), pulling force with one hand (a.5.4), static torque with two hands (a.5.5), and extremity muscle strength (a.5.6). Under sensorial capabilities (group b) includes under seeing (b.2): visual acuity (b.2.1), colour perception (b.2.2), field of view (b.2.3), glare (b.2.4), contrast (b.2.5), lighting level (b.2.6). Under touch (b.4), tactile spatial resolution (b.4.1), tactile temporal resolution (b.4.2), thermal sense (b.4.3). Under cognitive abilities (group c) and global (c.1), intellect (c.1.1), consciousness (c.1.2), energy (c.1.3), motivation (c.1.4). Under specific cognitive abilities (c.3): perception (c.3.1), attention (c.3.2), learning (c.3.3), memory (c.3.4), reasoning (c.3.5), problem solving (c.3.6), decision making (c.3.7), reading (c.3.8).

\subsection{Design related criteria}

The design related criteria, that refers to the built environment features, were critically reported following a user journey approach. One layer, with five main categories was identified, from first approaching the building, to accessing and living in the dwelling: (1) house location and surroundings, (2) building facilities and accessibility, (3) interior design features, (4) installations and technologies and (5) materials and finishes. These categories encompass all the areas related to the building, outdoors and indoors, and include specific design features that would tailor more accessible and inclusive spaces.

Four further layers were listed under each category and connected to the first layer.

The second layer includes for house location and surroundings (group 1): neighbourhood (1.1), outdoor connectors (1.2), parking (1.3), entrance (1.4).

Regarding building facilities and accessibility (group 2): spaces for socialising (2.1), spaces for activities (2.2), multipurpose (2.3), indoor connectors (2.4) Regarding interior design features (group 3): furniture (3.1), accessories (3.2), orientation and information (3.3). Regarding installations and technology (group 4): electrical (4.1), assistive technology (4.2), ventilation (4.3), lighting (4.4), heating (4.5).

Regarding materials and finishes (group 5): walls (5.1), ceilings (5.2), flooring (5.3), colours (5.4).

The third layer includes for house location and surroundings (group 1), under neighbourhood (1.1): urban infrastructure (1.1.1) and essential services (1.1.2). Under outdoor connectors (1.2): public related (1.2.1), private related (1.2.2). Under parking (1.3): communal parking spaces (1.3.1) and parking for houses (1.3.2). Under entrance (1.4): individual housing (1.4.1) and residential buildings (1.4.2).

Regarding building facilities and accessibility (group 2), and spaces for socialising (2.1): living room (2.1.1), dining room (2.1.2). Under spaces for activities (2.2): kitchen (2.2.1), bathroom (2.2.2), bedrooms (2.2.3). Under multipurpose (2.3): storage and laundry (2.3.1), study (2.3.2), private outdoor (2.3.3). Under indoor connectors (2.4): horizontal (2.4.1), vertical (2.4.2).

Regarding interior design features (group 3), under accessories (3.2): windows and blinds (3.2.1), doors (3.2.2), fittings (3.2.3), handrails (3.2.4), equipment, controls and switches (3.2.5). Under orientation and information (3.3): audible (3.3.1), tactile (3.3.2), visual (3.3.3).

Regarding installations and technology (group 4), under electrical (4.1): access control for dwellings (4.1.1). Under assistive technology (4.2): health (4.2.1), environment (4.2.2), communication and entertainment (4.2.3). Regarding materials and finishes (group 5), under colours (5.4): visual contrast (5.4.1). The fourth layer includes for neighbourhood (1.1), under urban infrastructure (1.1.1): planting (1.1.1.1), lighting (1.1.1.2), accessories (1.1.1.3). For outdoor connectors (1.2), under public (1.2.1): furniture lighting (1.2.1.1). Under private (1.2.2): gates and pathways (1.2.2.1), stepped paths (1.2.2.2), accessories (1.2.2.3). For entrance (1.4) under individual housing (1.4.1): accessories (1.4.1.1). Under residential buildings (1.4.2): accessories (1.4.1.2). For spaces for socializing (2.1) and living room (2.1.1): furniture (2.1.1.1), accessories (2.1.1.2), materials (2.1.1.3). Under dining room (2.1.2): furniture (2.1.2.1), accessories (2.1.2.2), materials (2.1.2.3).

For spaces for activities (2.2), under kitchen (2.2.1): furniture (2.2.1.1), accessories (2.2.1.2), materials (2.2.1.3). Under bathroom (2.2.2): toilet rooms (2.2.2.1), showers (2.2.2.2), baths (2.2.2.3), materials (2.2.2.4), furniture (2.2.2.5), accessories (2.2.2.6), installations (2.2.2.7). Under bedrooms (2.2.3): furniture (2.2.3.1), accessories (2.2.3.2), materials (2.2.3.3).

For multipurpose (2.3), under storage and laundry: furniture (2.3.1.1), accessories (2.3.1.2), materials (2.3.1.3). Under study (2.3.2): furniture (2.3.2.1), accessories (2.3.2.2), materials (2.3.2.3). Under private outdoor (2.3.3): gardens (2.3.3.1), terrace and balconies (2.3.3.2).

For indoor connectors (2.4), under horizontal (2.4.1): ramps (2.4.1.1), hallways and corridors (2.4.1.2), moving walks (2.4.1.3). Under vertical (2.4.2): stairs (2.4.2.1), escalators (2.4.2.2), lifts/elevators 
(2.4.2.3), platforms (2.4.2.4). For orientation and information (3.3), under visual (3.3.3): location and heights (3.3.3.1), lettering font and size (3.3.3.2), graphical symbols (3.3.3.3).

The fifth layer includes for bathroom (2.2.2), under toilet rooms (2.2.2.1): type "A" toilet (2.2.2.1.1), type "B" toilet (2.2.2.1.2), type "C" toilet (2.2.2.1.3), ambulant toilet (2.2.2.1.4). Under furniture (2.2.2.5): urinals (2.2.2.5.1), basins (2.2.2.5.2), storage and shelving (2.2.2.5.3).

For vertical connectors (2.4.2), under stairs (2.4.2.1): buildings (2.4.2.1.1), homes (2.4.2.1.2). Under lifts/elevators (2.4.2.2): buildings (2.4.2.2.1), homes (2.4.2.2.2). The resulting hierarchical maps of people's capabilities and dwelling design-related elements is shown in Figure 1 below.

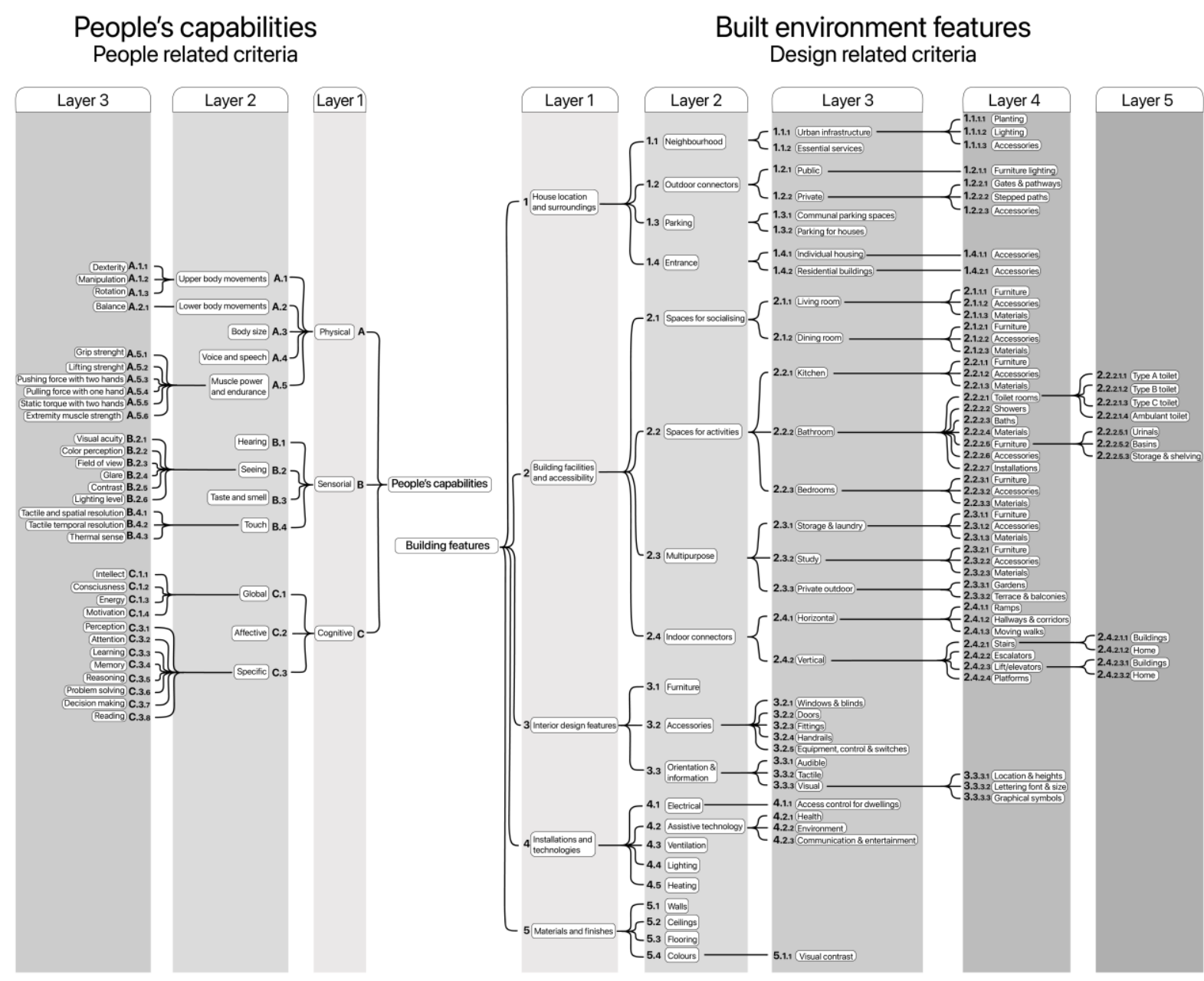

Figure 1. Hierarchical map of people related criteria (people's capabilities, left) and design related criteria (built environment features - right).

This figure shows a comprehensive ontology and clusters the identified criteria according to hierarchical layers illustrated through a user-friendly graphical representation. This figure represents a first attempt to build a comprehensive ontology to ease the understanding and learning process for engineering design professionals.

\section{DIScussion}

In people-centred design approaches (Mahmood and Keating, 2012) a phase called "needfinding" helps designers to explore the aspiration, attitudes, behaviour, needs and capabilities of the final user (Patnaik and Becker, 2010). In the civil engineering and architectural design practice approaches such as the Quality Function Deployment (Kiran, 2017) can help defining user needs and translating them into specific plans to produce products to meet those needs. Similarly, the capabilities map could work as a tool to inform a more effective needfinding process with the goal of acquiring empathic skills and a deeper understanding about the nature of desires and abilities.

The design requirements definition phase that stimulates the creative engineering design process (Pfeifer, 2009) could be reinforced by visualizing and understanding the broad sense of the needs that 
the design has to address. This would inform a design that answers to specific challenges identified through the needfinding stage with the people's capabilities map, without forgetting certain aspects.

On the other hand, the map with the built environment design related criteria can be integrated into the design requirements phase to improve the design process. The map with the design related criteria can additionally support designers to broaden with a holistic understanding the impact that their design has with the whole surroundings and with people.

Since ID is based on adapting the design demands to people's capabilities (sensorial, cognitive and physical) (Persad et al., 2007), highlighting the strict relationship between user capabilities and design requirements can improve the engineering design process and as an outcome, peoples' experience throughout the space. Research suggests that a similar approach can help to change professionals' attitudes towards guidelines and standards and improve the application of ID mindset (Heylighen et al., 2017). The ontology, with the hierarchical mapping could serve as a guide to improve initial phases of the engineering design process. However, a further fundamental application relates to what specific features are needed to advance in future steps of the design process, where designers seek to match people capabilities and building features with accessibility and usability.

An explorative implementation of this ontology could be to overlay its granularity in visualization with semantics of the user journeys. Displaying this relationship with a user-friendly infographic can help design engineers to evaluate a wider range of examples with the goal to create solutions to improve people's experience (Zallio, 2021).

Figure 2 displayed below shows an example of how the ontology can be framed within engineering design practice for the built environment. On the left, a fundamental need of a dwelling occupant is to move between floors. Some describers of this action can be found in the design related criteria and classified under building facilities and accessibility, vertical connections (map reference 2.4.2).

These are some of the basic design requirements to ensure that the user merely completes a task. In order to better frame how the design requirements would shape the final solution, a deeper understanding of the person's capabilities has to be verified. In relation to the action of moving between floors, the people related criteria highlight that special attention should be dedicated to physical, lower body movements and muscle power and endurance (map reference a.2.1; a.5.1; a.5.2; a.5.3; a.5.4; a.5.5; a.5.6); sensorial capabilities (map reference: b. $2.1 ;$ b.2.2; b.2.3; b.2.4; b.2.5; b.2.6; b.4.1; b.4.2; b.4.3), and cognitive abilities (map reference: c.1.1; c.1.2; c.1.3; c.1.4; c.3.1; c.3.2; c.3.3; c.3.6; c.3.7).

The bar below as well as the sample figures show examples of possible solutions that evolve along the decision-making process while including design related and people related criteria.

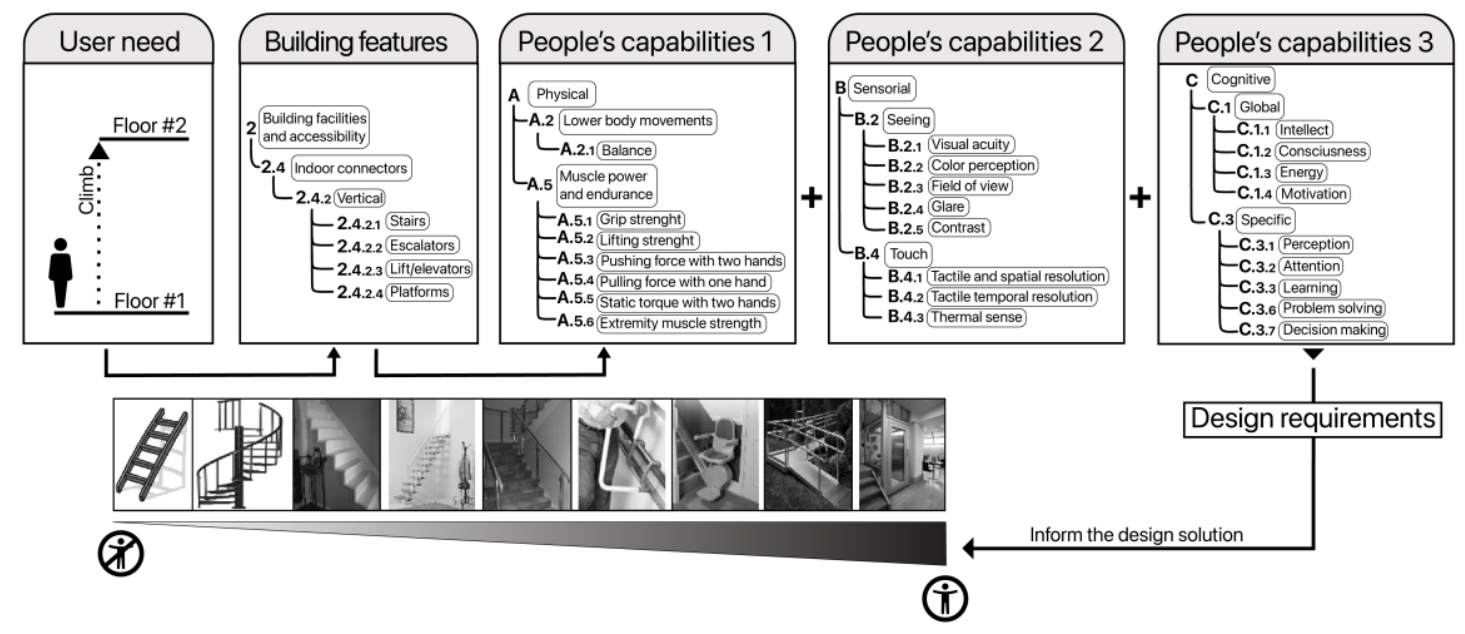

Figure 2. The figure shows an example of how the ontology can be framed within engineering design practice for the built environment with a case study of vertical connection.

Figure 3 shows a typical challenge of entering into a space and interacting with a door. Describers of this action can be found in the design related criteria and classified under interior design features, accessories, doors (map reference $3 ; 3.2 ; 3.2 .2$ ). In relation to the interaction with a door, people related criteria highlight that special attention should be dedicated to physical, upper body movements 
and muscle power and endurance (map reference: a.1.1, a.1.2, a.1.2; a.1.3; a.5.1; a.5.2; a.5.3; a.5.4; a.5.5; a.5.6), sensorial capabilities (map reference: b.2.1; b.2.2; b.2.3; b.2.4; b.2.5; b.4.1; b.4.2; b.4.3), and cognitive abilities (map reference: c. $1.1 ;$ c. $1.2 ;$ c.3.1; c.3.2; c.3.3; c.3.4; c.3.5; c.3.6; c.3.7).

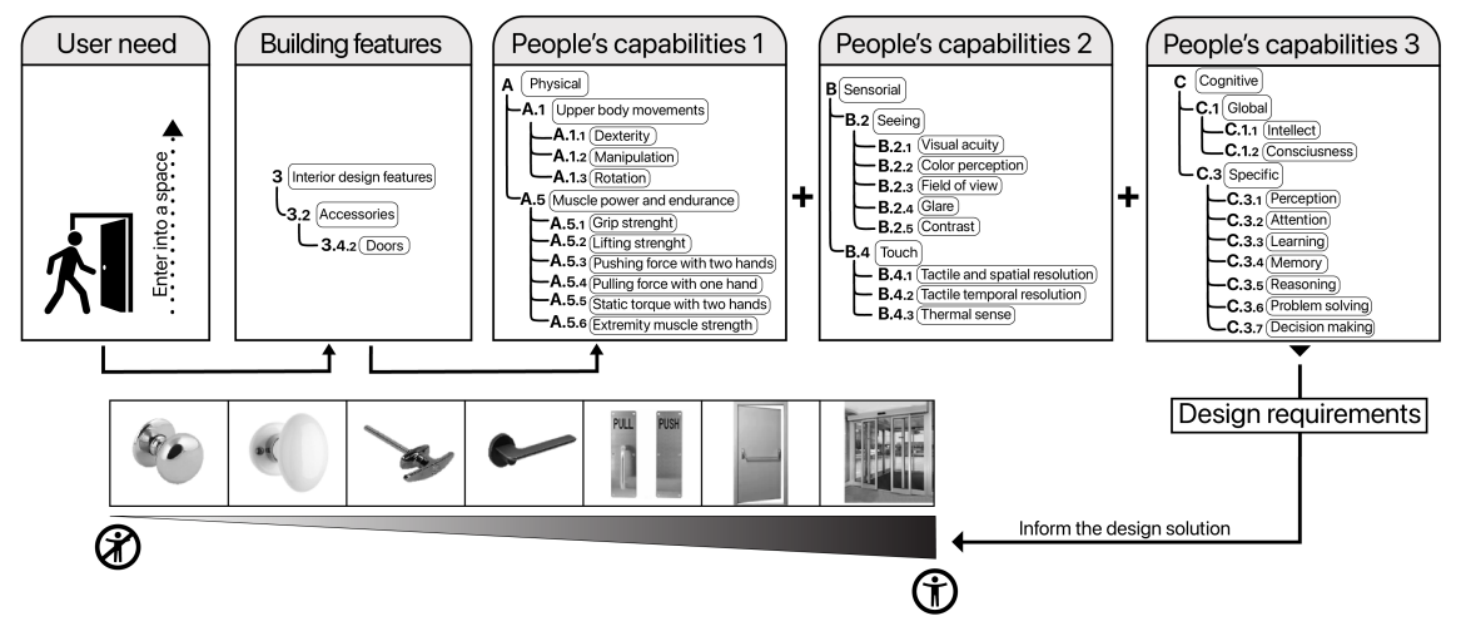

Figure 3. The figure shows an example of how the ontology can be framed within engineering design practice for the built environment with the case study of a door entrance.

The connotation with two pragmatic examples of the developed ontology shows how a comprehensive ontology has the potential to be transferred between several settings, contexts and design challenges. However, it is important to note that this constitutes an explorative ontology that analyses and visualizes a large variety of data, from different credited sources, with the aim to improve the understanding of the inclusive design process for sustainable, age friendly and smart environments. One limitation of this study relates to the current level of depth of single sub-group criteria. Currently we represented three layers for people related criteria and five for design related criteria. Further layers are currently under study and will be included in the second version of the ontology, with a higher level of details for each single sub-group, with detailed information about usability and accessibility criteria. Furthermore, an interactive tool for the selection of different features is under study.

The underlying concept behind the hierarchical ontology of people and design related built environment criteria represents an informative model that could see applications in several other domains: from engineering design, to architectural design, to service design, to user interface design and broadly to user experience design. A similar approach will be further deployed in the following research steps to improve the understanding of the variables for a people-centred design process.

\section{CONCLUSIONS}

This first step of the international project run in collaboration between research institutions and businesses from the engineering and construction sector represents a first attempt to analyse and map features that could potentially support engineering design practitioners to craft inclusive and accessible environments, products and services that enable ageing in place.

With this explorative research we aimed to bridge the gap between healthcare related knowledge on people's capabilities and design regulations. To achieve this goal, we identified design related built environment criteria as well as people related criteria that were hierarchically classified through an ontology expressed with graphical facilitators. The final scope was to ease the understanding of a large amount of data from different scientific and regulatory documents and to enable researchers and practitioners to better identify clusters of accessibility and inclusion criteria for the design of accessible, inclusive, smart, age-friendly environments.

This research strengthens the concept expressed in previous works from the authors (Zallio and Casiddu, 2016) towards the creation of systems to empower professionals and users to understand and categorize systems and features to develop smart, barrier-free dwellings. Further work has demonstrated that a means by which user capabilities, as defined in the ICF, can be matched to functionality of spaces or devices is of beneficial support not only to engineering design professionals, but also to the final user (Kelly et al., 2019). Although this study focused mostly on providing tools for design practitioners, the findings may as well have a bearing on policies for housing adaptations, 
building legislation to support ageing in place and on shaping social housing to offer more inclusive and comprehensive solutions.

A natural progression of this work will be to further explore how people's needs and capabilities could be implemented into supporting tools with an up-to-date match with regulations and policy documents to improve the design process for engineering design professionals.

We foresee this approach to quickly moving towards digital platforms with multimedia features that will allow a further impact on the audience and potentially bring a major benefit not only for professionals, but also for who is genuinely interested in the topic of accessibility an inclusion in the engineering design process. A key aspect of this work is to strive for a beneficial impact that improves the development of future inclusive tools to support stakeholders for designing mainstream environments that are adaptable, flexible and suitable for the changing needs of the whole population, by targeting a high level of well-being and people's satisfaction.

\section{ACKNOWLEDGEMENTS}

This project has received funding from the European Union's Horizon 2020 research and innovation programme under the Marie Skłodowska-Curie grant agreement $\mathrm{N}^{\circ} 846284$.

Ms. Claudia Ferndandez contributed to introduction, methodology, performed the literature review search, data analysis, discussion and contributed to develop the infographic material listed.

Dr. Matteo Zallio wrote the introduction, the state of the art, contributed to the research methodology, findings, conclusions sections and developed the infographic material.

Dr. Damon Berry wrote the conclusions and contributed to findings.

Dr. John McGrory wrote the findings and contributed to conclusions.

\section{REFERENCES}

Bowen, G.A. (2009), "Document analysis as a qualitative research method", Qualitative Research Journal, RMIT Publishing, Vol. 9 No. 2, pp. 27-40.

British Government. (1995), Disability Discrimination Act 1995, Statute Law Database, available at: https://www.legislation.gov.uk/ukpga/1995/50/contents (accessed 1 December 2020).

British Government. (2004), The Building Regulations 2004 - Access and Use of Buildings Part M.

British Standard Institute. (2009), "BS 8300-2:2018 Design of an accessible and inclusive built environment. Buildings. Code of practice", available at: https://shop.bsigroup.com/ProductDetail?pid=000000000030335835 (accessed 1 December 2020).

CEN and CENELEC. (2014), "CEN/CENELEC Guide 6:2014 - Guide for addressing accessibility in standards".

Centre for Excellence in Universal Design. (2012). Building for Everyone: A Universal Design Approach, available at: http://universaldesign.ie/Built-Environment/Building-for-Everyone/Entire-Series-Books1_10.pdf (accessed 1 December 2020a).

Centre for Excellence in Universal Design. (2015). "Universal Design Guidelines for Homes in Ireland | Centre for Excellence in Universal Design", available at: http://universaldesign.ie/Built-Environment/Housing/ (accessed 1 December 2020).

EIP on AHA, European Innovation partnership on Active and Healthy Ageing, available at: https://ec.europa.eu/eip/ageing/actiongroup/index/d4_en (accessed 1 December 2020).

EU-SHAFE, European Smart Healthy Age Friendly Environments, (2019), available at: https://www.interregeurope.eu/eushafe/ (accessed 1 December 2020).

Grant, M.J. and Booth, A. (2009), "A typology of reviews: An analysis of 14 review types and associated methodologies", Health Information and Libraries Journal, Health Info Libr J, Vol. 26 No. 2, pp. 91-108.

Hands-on SHAFE. (2019), available at: https://hands-on-shafe.eu/en (accessed 1 December 2020).

Heylighen, A., Van der Linden, V. and Van Steenwinkel, I. (2017), "Ten questions concerning inclusive design of the built environment", Building and Environment, Elsevier Ltd, Vol. 114, pp. 507-517.

International Standards Organization. (1994), ISO TR 9527 Building Construction-Needs of Disabled People in Buildings, available at: https://www.iso.org/standard/22799.html (accessed 3 December 2020).

International Standards Organization. (2001), "ISO - ISO/IEC Guide 71:2001 - Guidelines for standards developers to address the needs of older persons and persons with disabilities", available at: https://www.iso.org/standard/33987.html (accessed 1 December 2020).

International Standards Organization. (2008), "ISO/TR 22411:2008 - Ergonomics data and guidelines for the application of ISO/IEC Guide 71 to products and services to address the needs of older persons and persons with disabilities", available at: https://www.iso.org/standard/40933.html (accessed 1 December 2020).

International Standards Organization. (2011), ISO 21542 - Accessibility and Usability of the Built Environment. 
Keates, S., Clarkson, J., Langdon, P. and Robinson, P. (2004), Designing a More Inclusive World, Designing a More Inclusive World, Springer London, available at: https://doi.org/10.1007/978-0-85729-372-5.

Kelly, P., Zallio, M., Duarte, B. and Berry, D. (2019), "Design for enabling technologies. A framework to empower multi-level user engagement”, Advances in Intelligent Systems and Computing, Vol. 776, Springer Verlag, pp. 65-74.

Kiran, D.R. (2017). “Quality Function Deployment”, Total Quality Management, pp. 425-437, available at: https://doi.org/10.1016/C2016-0-00426-6.

Lyons, R., Sirr, L., Researc, A. and Delivery;, I. (2016), Housing for Older People - Thinking Ahead.

Mahmood, A. and Keating, N. (2012), "Towards inclusive built environments for older adults", From Exclusion to Inclusion in Old Age: A Global Challenge, Policy Press, pp. 145-162.

NET 4 AGE-FRIENDLY - International Interdisciplinary Network on Smart Healthy Age-friendly Environments". (2020). , available at: https://www.cost.eu/actions/CA19136/\#tabs\%7CName:overview (accessed 1 December 2020).

Patnaik, D. and Becker, R. (2010), “Needfinding: The Why and How of Uncovering People's Needs”, Design Management Journal (Former Series), Wiley-Blackwell, Vol. 10 No. 2, pp. 37-43.

Persad, U., Langdon, P., Brown, D. and Clarkson, P.J. (2007), "Cognitive scales and mental models for inclusive design", Lecture Notes in Computer Science (Including Subseries Lecture Notes in Artificial Intelligence and Lecture Notes in Bioinformatics), Vol. 4554 LNCS, Springer Verlag, pp. 776-785.

Pfeifer, M. (2009), "Design Requirements”, Materials Enabled Designs, pp. 23-50.

Saaty, R.W. (1987), "The analytic hierarchy process-what it is and how it is used", Mathematical Modelling, Pergamon, Vol. 9 No. 3-5, pp. 161-176.

Thomas, J. and McDonagh, D. (2013), "Empathic design: Research strategies", Australasian Medical Journal, Australasian Medical Journal, Vol. 6 No. 1, pp. 1-6.

TN SHAFE, Thematic Network on Smart Healthy Age Friendly Environments available at: https://ec.europa.eu/digital-single-market/en/news/smart-healthy-age-friendly-environments-networklaunches-joint-statement-policy-making (accessed 1 December 2020).

United Nations Department of Economic and Social Affairs. (1993), "Standard Rules on the Equalization of Opportunities for Persons with Disabilities | United Nations Enable", available at: https://www.un.org/development/desa/disabilities/standard-rules-on-the-equalization-of-opportunities-forpersons-with-disabilities.html (accessed 1 December 2020).

United Nations Department of Economic and Social Affairs. (2019), How Certain Are the United Nations Global Population Projections?, Population Facts No. 2019/6, Vol. 115, available at:https://doi.org/https://doi.org/10.2307/2808049.

United Nations Department of Economic and Social Affairs. (2020), World Population Ageing 2019, available at:https://doi.org/https://doi.org/10.18356/6a8968ef-en.

United Nations Development Program. (2016), "Sustainable development goals", available at: http://www.undp.org/content/undp/en/home/sustainable-development-goals.html (accessed 1 December 2020).

Van Ditmarsch, M. (2001), "Access for All - a Priority Theme for EDF - Activities in a Unifying Europe", EDF seminar on Universal Access, Luxembourg, Brussels, available at: http://www.eca.lu/index.php/documents/eucan-documents/15-eca-history-part-1/file

World Health Organisation. (2019), "Decade of healthy ageing 2020 - 2030", OMS.

World Health Organisation. (2001), "International Classification of Functioning", available at: https://apps.who.int/classifications/icfbrowser/ (accessed 1 December 2020).

World Health Organisation. (2014), Measuring the Age - Friendliness of Cities : A Guide to Using Core Indicators, WHO Report, Kobe, Japan, available at: https://apps.who.int/iris/bitstream/handle/10665/203830/9789241509695_eng.pdf;jsessionid=5528906A749 7A85A1BADC03FE2FB2769?sequence=1 (accessed 1 December 2020).

Zallio, M. and Casiddu, N. (2016), "Lifelong housing design: User feedback evaluation of smart objects and accessible houses for healthy ageing", ACM International Conference Proceeding Series, Vol. 29-June2016, Association for Computing Machinery, available at:https://doi.org/10.1145/2910674.2935828.

Zallio, M., Berry, D. \& Casiddu, N. (2016), “Adaptive homes for enabling senior citizens: A holistic assessment tool for housing design and IoT-based technologies". IEEE 3rd World Forum of Internet of Things (WfIoT). Reston VA, USA IEEE.

Zallio, M. (2021), "Democratizing information visualization. A study to map the value of graphic design to easier knowledge transfer of scientific research". In: Soares, M., Marcus, A. \& Rosenzweig, E. (eds.) Design, User Experience, and Usability. 10th International Conference, DUXU 2021, Held as Part of the 23nd HCI International Conference, HCII 2021. Washington, DC, USA, Springer. 